\title{
Changes in human epidermal growth factor receptor 2 status between primary breast/gastric carcinomas and synchronous metastatic lymph nodes: how can we explain them?
}

\author{
Antonio leni, Valeria Barresi, Giovanni Branca, Luana Licata, Rosario Alberto Caruso, Giovanni Tuccari \\ Department of Human Pathology "Gaetano Barresi”, University of Messina, 98125 Messina, Italy.
}

Correspondence to: Prof. Giovanni Tuccari, Department of Human Pathology "Gaetano Barresi”, A.O.U. Polyclinic G. Martino Via Consolare

Valeria 1, 98125 Messina, Italy. E-mail: tuccari@unime.it

\section{A B S T R A C T}

Aim: Previous studies demonstrated discordant expression of human epidermal growth-factor receptor 2 (HER2) between primary cancer and their recurrence/metastasis. This study further evaluated HER2 status between primary gastric and breast invasive carcinomas and paired metastatic disease to lymph nodes. Methods: This study collected formalin-fixed paraffin-embedded representative tissue blocks from 62 gastric and 65 breast primary carcinomas as well as synchronous metastatic lymph nodes (male:female $=39: 88$; age ranged between 44 and 95 years with mean age of 69.32 years) for immunohistochemical staining of HER2 expression (DAKO HercepTest ${ }^{\mathrm{TM}}$ kit). If immunohistochemical HER2 score reached to 2+, HER2 amplification was then assessed using fluorescence in situ hybridization (PharmDx ${ }^{\mathrm{TM}}$ kit DAKO). Results: The discordant HER2 pooled rate, regardless either negative or positive conversion, was $9.67 \%$ in primary gastric carcinoma and corresponding nodal metastasis, while the changes in HER2 expression were revealed in $4.61 \%$ of mammary and lymph node neoplastic samples. A high-level concordance in HER2 expression between primary carcinoma and synchronous metastatic lymph nodes was confirmed in both types of cancer; the observed event of discordant HER2 status should be ascribed to intra-tumor heterogeneity, mostly appreciable in gastric cancer. Conclusion: In any case, the shift from positive to negative HER2 expression suggests that trastuzumab could be the targeted treatment choice whereas the opposite shift should be evaluated by a simultaneous HER2 determination in both primary and metastatic lymph nodes.

Key words: Breast cancer, epidermal growth-factor receptor 2, gastric cancer, lymph node, metastasis

\section{Introduction}

Expression or amplification of human epidermal growth-factor receptor 2 (HER2) frequently occur in primitive neoplastic tissues from patients with breast carcinoma (BC) $\cdot^{[1-4]}$ However, in recent years, several studies have demonstrated that HER2 status may vary in the metastatic lesions compared to the primary tumor, ${ }^{[5-8]}$ and this discrepancy is more frequently found in distant metastases than in loco-regional ones. ${ }^{[9-13]}$ Discordance in HER2 status was not only found between primary $\mathrm{BC}$ and its metastases, but also among the consecutive relapses of the same tumor, with similar proportions of cases turning from negative to positive or vice versa and the changes mainly appeared in the second or following progressions. ${ }^{[13-16]}$

HER2 amplification may also be detected in gastric carcinomas (GCs), with a prevalence ranging between

\begin{tabular}{|l|l|}
\hline \multicolumn{2}{|c|}{ Access this article online } \\
\hline Quick Response Code: & Website: \\
\hline & www.jcmtjournal.com \\
\cline { 2 - 2 } & \\
\hline & DOI: \\
\hline
\end{tabular}

$7.7 \%$ and $25 \%$ depending on localization and histology of the cancer, ${ }^{[17-19]}$ a higher rate of HER2 amplification occurs in unusual aggressive histology types, such as the hepatoid variant. ${ }^{[20,21]}$ However, until date, there were only a few studies reporting HER2 heterogeneity in paired primary and metastatic GC samples, ${ }^{[22-24]}$ and demonstrating a low rate of discordance in HER2 amplification with either positive and negative conversion. ${ }^{[23,24]}$

The potential divergence in the HER2 status between the primitive $\mathrm{BC} / \mathrm{GC}$ and their metastasized diseases, or among the successive metastases of the same tumor, has a significant clinical relevance since it may modify the patient's sensitivity to targeted therapies, ${ }^{[8]}$ which might be appropriate for the primitive tumor, but not for the metastases or vice versa. ${ }^{[12-15]}$ For this reason, some investigators proposed that detection of HER2 status should be re-assessed in the neoplastic tissues from metastatic $\mathrm{BC}$ to establish whether the therapy is actually appropriate. ${ }^{[1,2,16,17]}$

Thus, in this study, we evaluated HER2 status in paired samples of $\mathrm{BC} / \mathrm{GC}$ and synchronous metastatic lymph nodes that were collected during the same surgical and tissue processing procedures, thus limiting and avoiding any potential technical bias due to external factors. Our aim was to explore the eventual HER2 discordance rate between primary 
BC and GC samples and corresponding lymph node metastases. The study was approved by review board of University of Messina.

\section{Methods}

This cohort contained 127 surgical BC and GC specimens, together with the corresponding regional synchronous metastatic lymph nodes. In brief, 65 primary $\mathrm{BC}$ and 62 primary GC (male:female $=39: 88$; age ranged between 44 and 95 years with mean age of 69.32 years) were retrospectively collected from the archive of the Department of Human Pathology at the University of Messina. No patients had received neo-adjuvant chemotherapy or other therapies before surgery.

The primary GC was classified for localization and histology type according to WHO 2010, Lauren's classification and HER2 status of the tumor were available for all cases. Similarly, histology, grade, hormone receptor status, Ki-67, and HER2 status were recorded for all $\mathrm{BC}$ cases. Patient identification was not disclosed in this publication, and all patients had provided written consent to their medical information being used for research purposes, according with the Helsinki declaration.

For each case, $3 \mu \mathrm{m}$ thick tissue sections from two different formalin-fixed paraffin-embedded representative tissue blocks of the primary tumor and metastatic lymph nodes (at least four for each case) were prepared and immunohistochemical stained for HER2 expression. In brief, the immunohistochemistry was carried out by using a DAKO HercepTest ${ }^{\mathrm{TM}}$ kit (Dako, Glostrup, Denmark) with an automated procedure (DAKO Autostainer Link 48) according to manufacturer's instructions. Antigen retrieval was performed by 3 cycles in $0.01 \mathrm{~mol} / \mathrm{L}$ citrate buffer $\mathrm{pH} 6.0$ in a microwave oven at $750 \mathrm{~W}$. For HER2 score was used to semiquantitatively assess HER2 expression level, that is, for the primary GC, 0 , absent staining; $1+$, faint and discontinuous membranous staining in $<10 \%$ of neoplastic elements; 2+, light to moderate lateral, baso-lateral or complete membranous staining in $>$ $10 \%$ of neoplastic elements; $3+$, strong, intense lateral, baso-lateral or complete staining in $>10 \%$ of neoplastic elements and for BC, 3+ score was defined when strong membranous staining was noted in at least $30 \%$ cells, $2+$ when weak to moderate complete membranous staining was evidenced in $10-30 \%$ of tumors cells, $1+$ when a faint or weak and incomplete membrane staining was observed and 0 when no staining was observed or when staining was present in $<10 \%$ of neoplastic cells.

Furthermore, fluorescence in situ hybridization (FISH) was performed using a HER2 FISH PharmDx ${ }^{\mathrm{TM}}$ kit (Dako) in those cases with HER2 immunostaining score for $2+$ or more. HER2 amplification was recorded when HER2 to CEP17 signal ratio was $>2.0$.
Fleiss-Cohen weighted $\mathrm{K}$ statistics was used to assess the concordance rate between HER2 status of the primary carcinomas and metastatic synchronous lesions. $\mathrm{K}$ values between 0 and 0.2 were regarded as no agreement, between 0.21 and 0.4 as fair agreement, between 0.41 and 0.6 as moderate agreement, between 0.61 and 0.8 as substantial agreement, and between 0.81 and 1 as almost perfect agreement. The statistical association between HER2 status and the other histopathological parameters was assessed using Chi-squared test. $P<0.05$ was considered statistically significant. All statistical analyses were performed using the SPSS package version 6.1.3 (SPSS, Chicago, IL, USA).

\section{Results}

Thirty GC cases $(48.40 \%)$ were localized in the lower third of the stomach, $22(35.48 \%)$ in the middle third and $10(16.12 \%)$ in the upper-third (four of which were localized at gastro-esophageal junction). Thirty-five GC cases $(56.45 \%)$ were diagnosed histopathologically according to the WHO criteria as adenocarcinoma (tubular, papillary, tubulo-papillary, and mucinous), 20 cases $(32.25 \%)$ as poorly cohesive carcinoma, and 7 cases $(11.30 \%)$ were mixed both. According to Lauren's classification, 35 cases $(56.45 \%)$ were classified as intestinal type, 20 cases $(32.25 \%)$ as diffuse and 7 cases $(11.30 \%)$ as mixed. Thirty-two of these 62 primary GC $(51.61 \%)$ were recorded as low-grade tumors, while 30 cases were high grade $(48.39 \%)$. HER2 immunohistochemical staining showed that 11 primary GCs $(17.74 \%)$ were scored for $3+$ HER2 expression, while 4 cases were $2+(6.42 \%)$, 5 cases $1+(8.10 \%)$, and 42 cases $(67.74 \%)$ were not expressed HER2 at all. FISH analysis revealed no amplification in all of these cases with HER2 scores of $2+$ or more. Taken together, in primary GC, HER2 was overexpressed in 11 cases $(17.74 \%)$ but there was no HER2 amplification in 51 cases $(82.26 \%)$. The overall concordance rate of HER2 status in primary GC between corresponding synchronous metastases was $90.32 \%$, whereas a change in HER2 status was observed in $6(9.68 \%)$ [Table 1], e.g. 4 cases with HER2 amplification in the primary GC but no amplification in the metastasized tumors [negative conversion; Figure 1a and b], two of these discordant cases did not show HER2 amplifications in the primitive tumor but amplified in the lymph node metastases [positive conversion; Figure $1 \mathrm{c}$ and $\mathrm{d}$ and Table 2].

In the primary $\mathrm{BC}$, the most frequent histology type was ductal invasive carcinomas with the following grading: 4 G1 (6.25\%), 28 G2 (43\%), and 33 G3 (50.75\%). HER2 overexpression occurred in 14 (21.53\%) of primary BC, 4 (6.15\%) of which exhibited a score $2+$, $2(3.09 \%)$ a score $1+$, while $45(69.23 \%)$ cases didn't 
express HER2 at all. FISH analysis was conducted in those cases with the HER2 score of $2+$ or more and

Table 1: Clinicopathological and HER2 concordance in 62 GC patients

\begin{tabular}{|c|c|c|c|}
\hline & Discordant GC & Concordant GC & $P$ \\
\hline \multicolumn{4}{|l|}{ Gender } \\
\hline Male & 4 & 36 & 0.739 \\
\hline Female & 2 & 20 & \\
\hline \multicolumn{4}{|l|}{ Site } \\
\hline Lower & 3 & 27 & 0.389 \\
\hline Middle & 1 & 21 & \\
\hline Upper & 2 & 8 & \\
\hline \multicolumn{4}{|l|}{ Lauren histotype } \\
\hline Intestinal & 3 & 31 & 0.369 \\
\hline Diffuse & 1 & 19 & \\
\hline Mixed & 2 & 6 & \\
\hline \multicolumn{4}{|l|}{ WHO histotype } \\
\hline Tubular & 4 & 31 & 0.672 \\
\hline Poorly cohesive & 1 & 19 & \\
\hline Mixed & 1 & 6 & \\
\hline \multicolumn{4}{|l|}{ Grade } \\
\hline Low & 4 & 28 & 0.728 \\
\hline High & 2 & 28 & \\
\hline \multicolumn{4}{|l|}{ Stage } \\
\hline I-II & 3 & 21 & 0.875 \\
\hline III-IV & 3 & 35 & \\
\hline \multicolumn{4}{|l|}{$\mathrm{T}$} \\
\hline $1-2$ & 2 & 18 & 0.689 \\
\hline $3-4$ & 4 & 38 & \\
\hline \multicolumn{4}{|l|}{$\mathrm{N}$} \\
\hline 1 & 3 & 24 & 0.922 \\
\hline $2-3$ & 3 & 32 & \\
\hline
\end{tabular}

GC: Gastric carcinoma; HER2: Human epidermal growth factor receptor 2

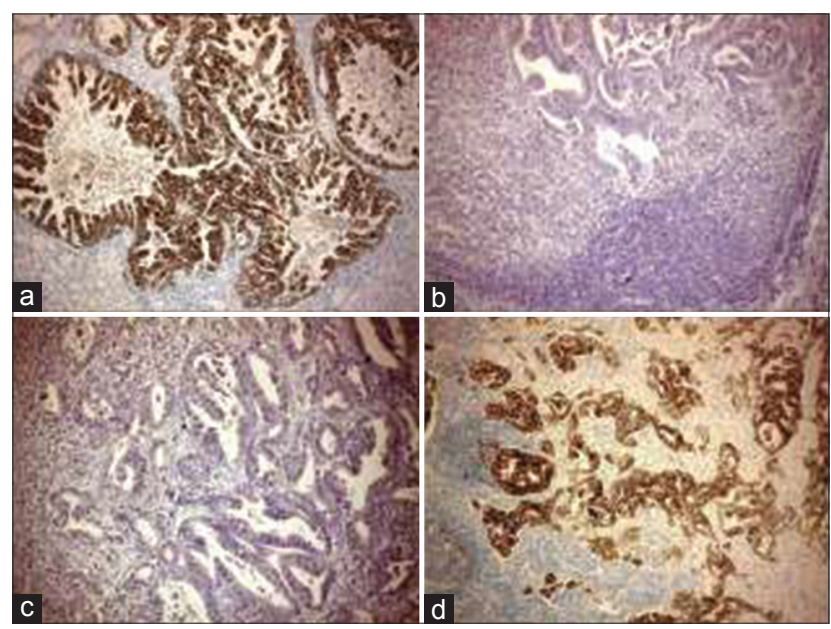

Figure 1: Expression of HER2 protein. A score of $3+\mathrm{HER} 2$ expression was encountered in neoplastic elements in a primary GC $(a, \times 200)$ but vanished in the corresponding metastatic lymph node (negative conversion) $(b, \times 160)(I H C$, Mayer's hematoxylin counterstain). HER2 immunohistochemical negative staining in primary GC (c, $\times 200)$, demonstrated a positive reactivity in the metastatic synchronous lymph node (positive conversion) (d, ×200) (IHC, Mayer's hematoxylin counterstain). HER2: Human epidermal growth factor receptor 2; GC: Gastric carcinomas; IHC: Immunohistochemistry the data revealed no HER2 amplification in these cases. Among $1+$ cases, FISH was carried out in only two selected carcinomas showing high grade, high Ki-67 value, $\mathrm{N}+$ status, and the absence of endocrine receptors expression, but no HER2 amplification was identified. HER2 was amplified in 14 BC cases (21.54\%) but there was no HER2 amplification in these 51 cases $(78.46 \%)$. The overall concordance rate was $95.39 \%$, whereas changes in HER2 status between primary carcinoma and corresponding synchronous metastases were evidenced in $3(4.61 \%)$ cases [Table 3]. Two of the discordant cases were HER2 negative in the primitive tumor but positive in the metastasized tumors [Figure 2a and b], whereas one case was HER2 positive in the primary $\mathrm{BC}$ and turned to negative in the metastatic tumor [Figure 2c and $\mathrm{d}$ and Table 4].

After that, we performed statistical analyses and found that the $\mathrm{K}$ value for the concordance rate in the HER2 status between primitive tumors and metastases was 0.651 (substantial agreement). HER2 amplification was significantly more frequent in the intestinal-type GC than that of diffuse-type while no significant differences in HER2 expression were noted among BC histology types. No statistical significant correlation emerged between HER2 and clinicopathological parameters (hormone receptors, growth fraction, $\mathrm{pT}, \mathrm{pN}$, and grade) either in $\mathrm{GC}$ as well as $\mathrm{BC}$.

\section{Discussion}

In the current study, we retrospectively analyzed HER2 expression in surgical GC and BC specimens versus the corresponding metastatic lymph nodes. Our results firstly confirmed the presence of a high level of concordance in HER2 status between the primary $\mathrm{GC} / \mathrm{BC}$ and their corresponding lymph node

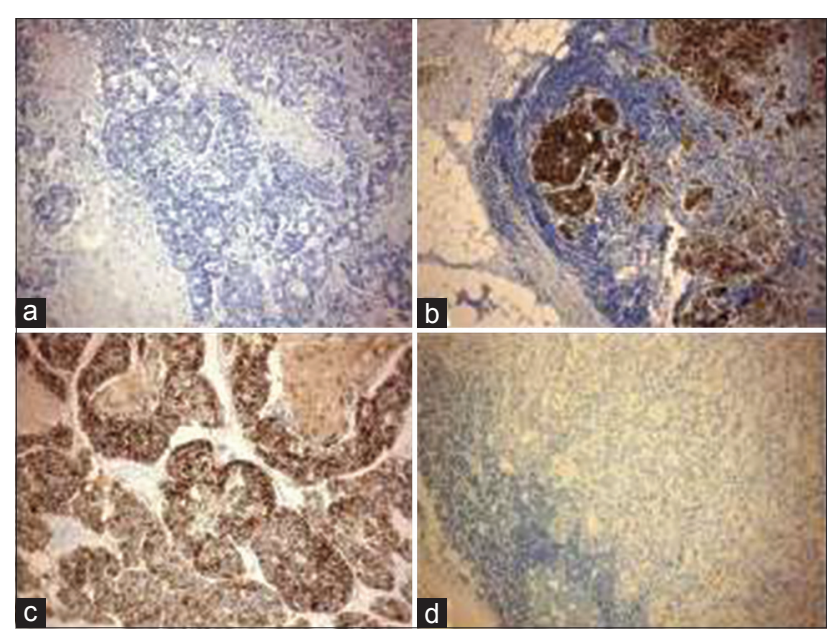

Figure 2: Expression of HER2 protein. A negative HER2 immunostaining in a primary infiltrative ductal carcinoma $(a, \times 160)$ became positive in the lymph node metastasis (positive conversion) $(b, \times 120)$. The strong and complete HER2 immunoreactivity in a case of primary BC $(c, \times 200)$ was not present in the synchronous lymph nodal metastasis (negative conversion) $(d, \times 200)(I H C$, Mayer's hematoxylin counterstain). HER2: Human epidermal growth factor receptor 2; BC: Breast carcinoma; IHC: Immunohistochemistry 
Table 2: HER2 discordant status in primary GC and corresponding synchronous nodal metastases

\begin{tabular}{lccllccc}
\hline Sex & Stage & p & pN & Histotype & Grade & Primary & Metastatic \\
& & & & & & GC & LN \\
\hline Male & III & 3 & 3 & Mixed & High & $3+$ & 0 \\
Female & III & 2 & 3 & Intestinal & Low & $3+$ & 0 \\
Male & II & 2 & 1 & Intestinal & Low & $3+$ & $1+$ \\
Male & III & 2 & 3 & Intestinal & Low & $3+$ & 0 \\
Male & II & 3 & 1 & Mixed & Low & 0 & $3+$ \\
Male & II & 3 & 1 & Diffuse & High & $2+*$ & $3+$ \\
\hline
\end{tabular}

*Not amplified by FISH. LN: Lymph node; GC: Gastric carcinoma; HER2: Human epidermal growth factor receptor 2; FISH: Fluorescence in situ hybridization

Table 3: Clinicopathological and HER2 concordance in 65 BC patients

\begin{tabular}{|c|c|c|c|}
\hline & Discordant BC & Concordant BC & $\boldsymbol{P}$ \\
\hline \multicolumn{4}{|l|}{ ER status } \\
\hline $\mathrm{ER}+$ & 2 & 47 & 0.743 \\
\hline $\mathrm{ER}-$ & 1 & 15 & \\
\hline \multicolumn{4}{|l|}{ PR status } \\
\hline $\mathrm{PR}+$ & 2 & 45 & 0.662 \\
\hline $\mathrm{PR}-$ & 1 & 17 & \\
\hline \multicolumn{4}{|l|}{ Ki-67 } \\
\hline $\mathrm{KI} \leq 14 \%$ & 1 & 16 & 0.701 \\
\hline $\mathrm{KI}>14 \%$ & 2 & 46 & \\
\hline \multicolumn{4}{|l|}{ Grade } \\
\hline G1 & 1 & 3 & 0.07 \\
\hline $\mathrm{G} 2$ & 0 & 28 & \\
\hline G3 & 2 & 31 & \\
\hline \multicolumn{4}{|l|}{$\mathrm{T}$} \\
\hline $1-2$ & 2 & 39 & 0.630 \\
\hline $3-4$ & 1 & 23 & \\
\hline \multicolumn{4}{|l|}{$\mathrm{N}$} \\
\hline 1 & 2 & 22 & 0.630 \\
\hline $2-3$ & 1 & 40 & \\
\hline
\end{tabular}

BC: Breast carcinoma; HER2: Human epidermal growth factor receptor 2; ER: Estrogen receptors; PR: Progesterone receptor

Table 4: HER2 discordant status in primary BC and corresponding synchronous nodal metastases

\begin{tabular}{lccccccc}
\hline pT & pN & Grading & $\begin{array}{c}\text { ER } \\
\mathbf{\%}\end{array}$ & $\begin{array}{c}\text { PR } \\
\mathbf{\%}\end{array}$ & $\begin{array}{c}\text { Ki-67 } \\
\mathbf{\%}\end{array}$ & $\begin{array}{c}\text { Primary } \\
\text { BC }\end{array}$ & $\begin{array}{c}\text { Metastatic } \\
\text { LN }\end{array}$ \\
\hline T2 & N3 & G3 & 90 & 15 & 20 & $3+$ & 0 \\
T1c & N1 & G1 & 80 & 80 & 10 & $3+$ & $1+*$ \\
T3 & N1 & G3 & 0 & 0 & 20 & 0 & $3+$ \\
\hline
\end{tabular}

*Not amplified by FISH. HER2: Human epidermal growth factor receptor 2; ER: Estrogen receptors; PR: Progesterone receptor; BC: Breast carcinoma; LN: Lymph node; FISH: Fluorescence in situ hybridization

metastases (90.32\% and $95.39 \%$ respectively), which is consistent with previous observations of metachronous metastases (87.5-94.9\%). ${ }^{[19,23,25]}$ Moreover, we also found evidence of HER2 differences between primary carcinomas and their nodal metastases, that is, $9.68 \%$ $\mathrm{GC}$ cases and $4.61 \% \mathrm{BC}$ cases did have the discordance between the primary and secondary tumors. Specifically, four cases had HER2 amplifications in the primary GC but there were no HER2 amplifications in the metastatic tumors. In contrast, two of the gastric discordant cases showed no HER2 amplifications in the primitive tumor but amplified in the lymph node metastatic tumors. Similarly, there were two of the discordant BC cases showed negative HER2 in the primitive tumor but became positive in the metastatic tumors, whereas one case was from positive HER2 in the primary BC to negative in the metastases. Therefore, a positive or negative conversion was encountered in either GC or $\mathrm{BC}$ cases, although with a different discordance rate. A possible explanation for the discordance observed in $\mathrm{GC}$ than in $\mathrm{BC}$ cases could be attributed to the most frequent occurrence of a heterogeneity in GC cases, compared to BC. ${ }^{[18,21,26]}$ Hence, the biopsies or tissue microarray assays do not seem adequate for assessment of HER2 expression, in contrast to that elsewhere reported. ${ }^{[27,28]}$ In addition, the multisampling method performed in this study using at least two tissue blocks of primary tumors and four of metastatic lymph nodes could identify more discordant cases and compensate a potential heterogeneous HER2 expression. The possible explanation of HER2 positive conversion may be related to the selection of a new HER2 positive clone in metastatic lymph nodes as a result of disease progression. ${ }^{[29]}$ Loss of HER2 amplification (negative conversion) in metastatic tumors could not be only attributed to the development of resistance to trastuzumab therapy since our patients had not been subjected to any neo-adjuvant treatment. ${ }^{[29]}$

Changes in HER2 status between primary GC/BC and synchronous lymph node metastases may have relevant clinical impact. For example, only HER2 positive GC and $\mathrm{BC}$ currently support the use of trastuzumab in these patients; thus, our present finding suggests a need to reassess HER2 status before trastuzumab treatment. As a matter of fact, assessment of HER2 expression in the primary GC and BC may exclude from the targeted treatment a significant percentage of patients with a negative primary tumor, but positive metastases. Finally, the influence of discordant HER2 status in the therapeutic management as well as in the prognostic impact of patients affected by $\mathrm{GC}$ and $\mathrm{BC}$ should be greatly considered in order to correctly identify possible eligible candidates for trastuzumab-based therapy, even among patients with HER2 negative primary carcinomas.

\section{References}

1. Ieni A, Barresi V, Caltabiano R, Cascone AM, Del Sordo R, Cabibi D, Zeppa P, Lanzafame S, Sidoni A, Franco V, Tuccari G. Discordance rate of HER2 status in primary 
breast carcinomas versus synchronous axillary lymph node metastases: a multicenter retrospective investigation. Onco Targets Ther 2014;7:1267-72.

2. Ieni A, Barresi V, Giuffrè $G$, Caltabiano R, Cascone A, Del Sordo R, Cabibi D, Zeppa P, Lanzafame S, Sidoni A, Franco V, Tuccari G. Letter to the Editor regarding the paper by Aurilio et al. A meta-analysis of oestrogen receptor, progesterone receptor and human epidermal growth factor receptor 2 discordance between primary breast cancer and metastases. Eur J Cancer 2014;50:1035-7.

3. Aitken SJ, Thomas JS, Langdon SP, Harrison DJ, Faratian D. Quantitative analysis of changes in ER, PR and HER2 expression in primary breast cancer and paired nodal metastases. Ann Oncol 2010;21:1254-61.

4. Chan A, Morey A, Brown B, Hastrich D, Willsher P, Ingram D. A retrospective study investigating the rate of HER2 discordance between primary breast carcinoma and locoregional or metastatic disease. BMC Cancer 2012;12:555.

5. Hoefnagel LD, Moelans CB, Meijer SL, van Slooten HJ, Wesseling P, Wesseling J, Westenend PJ, Bart J, Seldenrijk CA, Nagtegaal ID Oudejans J, van der Valk P, van Gils $\mathrm{CH}$, van der Wall E, van Diest PJ. Prognostic value of estrogen receptor $\alpha$ and progesterone receptor conversion in distant breast cancer metastases. Cancer 2012;118:4929-35.

6. Aurilio G, Disalvatore D, Pruneri G, Bagnardi V, Viale G, Curigliano G, Adamoli L, Munzone E, Sciandivasci A, De Vita F, Goldhirsch A, Nolè F. A meta-analysis of oestrogen receptor, progesterone receptor and human epidermal growth factor receptor 2 discordance between primary breast cancer and metastases. Eur $J$ Cancer 2014;50:277-89.

7. Curtit E, Nerich V, Mansi L, Chaigneau L, Cals L, Villanueva C, Bazan F, Montcuquet P, Meneveau N, Perrin S, Algros MP, Pivot X. Discordances in estrogen receptor status, progesterone receptor status, and HER2 status between primary breast cancer and metastasis. Oncologist 2013;18:667-74.

8. Penault-Llorca F, Coudry RA, Hanna WM, Osamura RY, Rüschoff J, Viale G. Experts' opinion: Recommendations for retesting breast cancer metastases for HER2 and hormone receptor status. Breast 2013;22:200-2.

9. Regitnig $\mathrm{P}$, Schippinger W, Lindbauer $\mathrm{M}$, Samonigg $\mathrm{H}$, Lax SF. Change of HER-2/neu status in a subset of distant metastases from breast carcinomas. $J$ Pathol 2004;203:918-26.

10. Santinelli A, Pisa E, Stramazzotti D, Fabris G. HER-2 status discrepancy between primary breast cancer and metastatic sites. Impact on target therapy. Int $J$ Cancer 2008;122:999-1004.

11. Lindström LS, Karlsson E, Wilking UM, Johansson U, Hartman J, Lidbrink EK, Hatschek T, Skoog L, Bergh J. Clinically used breast cancer markers such as estrogen receptor, progesterone receptor, and human epidermal growth factor receptor 2 are unstable throughout tumor progression. $J$ Clin Oncol 2012;30:2601-8.

12. Houssami N, Macaskill P, Balleine RL, Bilous M, Pegram MD. HER2 discordance between primary breast cancer and its paired metastasis: tumor biology or test artefact? Insights through meta-analysis. Breast Cancer Res Treat 2011;129:659-74.

13. Cardoso F, Harbeck N, Fallowfield L, Kyriakides S, Senkus E. ESMO Guidelines Working Group. Locally recurrent or metastatic breast cancer: ESMO Clinical Practice Guidelines for diagnosis, treatment and follow-up. Ann Oncol 2012;23 Suppl 7:vii11-9.
14. Pérez-Fidalgo JA, Eroles P, Ferrer J, Bosch A, Burgués O, Martínez F, Bermejo B, Lluch A, González-Angulo AM. An evaluation of the impact of technical bias on the concordance rate between primary and recurrent tumors in breast cancer. Breast 2013;22:974-9.

15. Turner NH, Di Leo A. HER2 discordance between primary and metastatic breast cancer: assessing the clinical impact. Cancer Treat Rev 2013;39:947-57.

16. Idirisinghe PK, Thike AA, Cheok PY, Tse GM, Lui PC, Fook-Chong S, Wong NS, Tan PH. Hormone receptor and c-ERBB2 status in distant metastatic and locally recurrent breast cancer. Pathologic correlations and clinical significance. Am J Clin Pathol 2010;133:416-29.

17. Kim JH, Kim MA, Lee HS, Kim WH. Comparative analysis of protein expressions in primary and metastatic gastric carcinomas. Hum Pathol 2009;40:314-22.

18. Rüschoff J, Dietel M, Baretton G, Arbogast S, Walch A, Monges G, Chenard MP, Penault-Llorca F, Nagelmeier I, Schlake W, Höfler H, Kreipe HH. HER2 diagnostics in gastric cancer-guideline validation and development of standardized immunohistochemical testing. Virchows Arch 2010;457:299-307.

19. Kim MA, Lee HJ, Yang HK, Bang YJ, Kim WH. Heterogeneous amplification of ERBB2 in primary lesions is responsible for the discordant ERBB2 status of primary and metastatic lesions in gastric carcinoma. Histopathology 2011;59:822-31.

20. Rüschoff J, Hanna W, Bilous M, Hofmann M, Osamura RY, Penault-Llorca F, van de Vijver M, Viale G. HER2 testing in gastric cancer: a practical approach. Mod Pathol 2012;25:637-50.

21. Giuffrè G, Ieni A, Barresi V, Caruso RA, Tuccari G. HER2 status in unusual histological variants of gastric adenocarcinomas. J Clin Pathol 2012;65:237-41.

22. Barresi V, Giuffrè G, Caruso RA, Tuccari G. HER2 status in rarer histologic types of gastric adenocarcinomas. Arch Pathol Lab Med 2013;137:741.

23. Bozzetti C, Negri FV, Lagrasta CA, Crafa P, Bassano C, Tamagnini I, Gardini G, Nizzoli R, Leonardi F, Gasparro D, Camisa R, Cavalli S, Silini EM, Ardizzoni A. Comparison of HER2 status in primary and paired metastatic sites of gastric carcinoma. Br J Cancer 2011;104:1372-6.

24. Kochi M, Fujii M, Masuda S, Kanamori N, Mihara Y, Funada T, Tamegai H, Watanabe M, Suda H, Takayama T. Differing deregulation of HER2 in primary gastric cancer and synchronous related metastatic lymph nodes. Diagn Pathol 2013;8:191.

25. Marx AH, Tharun L, Muth J, Dancau AM, Simon R, Yekebas E, Kaifi JT, Mirlacher M, Brümmendorf TH, Bokemeyer C, Izbicki JR, Sauter G. HER-2 amplification is highly homogenous in gastric cancer. Hum Pathol 2009;40:769-77.

26. Hofmann M, Stoss O, Shi D, Büttner R, van de Vijver M, Kim W, Ochiai A, Rüschoff J, Henkel T. Assessment of a HER2 scoring system for gastric cancer: results from a validation study. Histopathology 2008;52:797-805.

27. Ataseven B, Gologan D, Gunesch A, Kehl V, Hoegel B, Beer M, Eiermann W. HER2/neu, Topoisomerase 2a, Estrogen and Progesterone Receptors: Discordance between Primary Breast Cancer and Metastatic Axillary Lymph Node in Expression and Amplification Characteristics. Breast Care (Basel) 2012;7:465-70.

28. Falck AK, Bendahl PO, Chebil G, Olsson H, Fernö M, Rydén L. Biomarker expression and St Gallen molecular subtype classification in primary tumours, synchronous lymph node metastases and asynchronous relapses in 
primary breast cancer patients with 10 years' follow-up. Breast Cancer Res Treat 2013;140:93-104.

29. Ieni A, Barresi V, Caltabiano R, Caleo A, Bonetti LR, Lanzafame S, Zeppa P, Caruso RA, Tuccari G. Discordance rate of HER2 status in primary gastric carcinomas and synchronous lymph node metastases: a multicenter retrospective analysis. Int J Mol Sci 2014;15:22331-41.
How to cite this article: leni A, Barresi V, Branca G, Licata L, Caruso RA, Tuccari $G$. Changes in human epidermal growth factor receptor 2 status between primary breast/gastric carcinomas and synchronous metastatic lymph nodes: how can we explain them? J Cancer Metastasis Treat 2015;1:21-6.

Received: 23-01-2015; Accepted: 02-03-2015.

Source of Support: Nil, Conflict of Interest: None declared. 